\title{
Study on Evolutionary Mechanisms of Corporate Knowledge Based on the Bionics View
}

\author{
Wang Dong-ling ${ }^{1,2, a}$, Kelvin C.K. Lam ${ }^{2, b}$ \\ ${ }^{1}$ Shandong Yingcai University, Jinan, Shandong, 250104 \\ ${ }^{2}$ China-ASEAN International College Dhurakij Pundit University, Bangkok, Thailand \\ a email:40668058@qq.com, b email: 2094752921@qq.com
}

Keywords: Corporate Knowledge Gene, Bionics View, A Model of Corporate Knowledge Gene Evolvement

Abstract: This dissertation starts with life-like properties of knowledge evolvement and discusses the mechanisms of corporate knowledge evolvement, i.e. fundamental mechanism, developing mechanism and innovative mechanism by using theories such as selforganization.

\section{Introduction}

The existent research results have shown that the understanding of the nature of enterprise has gone through some different evolutionary stages from production function, collection of contract, resource collection, collection ability, knowledge collection, then to the later complex systems and life forms. The more insightful understandings made it possible to explain the rules of corporate knowledge innovation more realistically. At the same time, the double helix structure in life science was proposed, making people understand the importance of genes in the organism better. As a result, regarding an enterprise as a living thing and exploring the evolution and development of corporate knowledge in terms of biology genes has drawn greater concern, and gradually formed a diversity of views on corporate knowledge genes, which to some extent has enriched the theory of corporate knowledge management. Nevertheless, the definitions on corporate knowledge genes, gene structure and other issues have not yet been agreed on among scholars. The mechanism research on how corporate knowledge genes affect corporate knowledge innovation to achieve sustainable growth by optimizing corporate knowledge genes is relatively weak. Thus, some problems, such as the analysis of the corporate knowledge genes from the origin, identification of corporate knowledge genetic factors, analysis on how corporate knowledge genes affect corporate knowledge innovation and building a unified theoretical framework for corporate knowledge innovation research on the basis of genes remains to be further deepened.

\section{Definitions of the Study}

In fact, various behaviors and phenomena in the process of the evolution of corporate knowledge are not only influenced by the structure and function of micro-units system, but also by the result of more complex interactions between constituents or the various elements. Dosi pointed out that the structure and function of the various components are important, but more importantly, the interaction between the components and how they interact to achieve the corresponding functions can not be 
ignored. Understanding these issues requires in-depth analysis on how various components form different functional structure through interaction and influence. Aldrich believed that the living organism is not a simple assembly of molecules, understanding the behavior of living systems must start from the system level. This further indicates that to study corporate knowledge innovation from gene should not only understand the basic components of corporate knowledge gene, but also clarify how genes play a role. Yet, it is the intrinsic differences in different function structure and dynamic characteristics formed by interaction and mutual influence between all sorts of corporate knowledge genetic elements that make innovative businesses changing remarkably in their external behaviors during the process of growth, which ultimately determines its ability to achieve sustainable growth. These key issues still need further studies that can also help provide new evidence for the study of corporate knowledge innovation from the genetic level, and deepen theory research on corporate knowledge genes affecting corporate knowledge innovation. Therefore, the subject matter of biological research in system science is introduced into the corporate knowledge innovation on the basis of genes to analyze how the corporate knowledge genetic factors and their interaction affect the corporate knowledge innovation behaviors which helps deepen the theoretical study of the corporate knowledge genes.

\section{Evolutionary Mechanisms of Corporate Knowledge Based on the Bionics View}

This dissertation starts with life-like properties of knowledge evolvement and discusses the mechanisms of corporate knowledge evolvement, i.e. fundamental mechanism, developing mechanism and innovative mechanism by using theories such as self-organization. It sets up a model to simulate the process of knowledge evolvement in an enterprise through certain kind of software. Its contents mainly cover the following 6 sections:

3.1 To construct a biological evolution model of corporate knowledge on the basis of knowledge fermentation model, with the concept of the knowledge gene introduced into the theory and the model.

The model consists of five elements: the theme (initial genome), the main body (knowledge gene groups of massive scattered knowledge gene), and the knowledge gene (the knowledge matrix, amounts of information and phenomena, catalyst (knowledge enzyme) and environmental factors (environmental impact of the surroundings). The main idea of the model is that a new research subject (a kind of knowledge innovation),which is produced by connecting parts of knowledge genes with the main body containing a vast of knowledge genes, will be continually enriched to produce newer knowledge in the influence of the external environment and the stimulation of the catalyst. The theory of biological evolution and gene is introduced into the model, with the attempt to be more concerned with the knowledge with biological characteristics, and more focused on the law of knowledge itself

\subsection{The corporate knowledge gene is composed of the internal structure and external mechanism.}

The internal structure of enterprise's knowledge gene is formed by five kinds of basic elements of entrepreneur resources, financial resources, human resources, technical resources and knowledge resources according to a certain or certain rules in different ways, which determines its function. The difference between the quality and quantity and the way of its combination determine the differences and results of the knowledge between different enterprises. It is the interaction between elements of the corporate knowledge gene that results in the emergence of a whole enterprise system, making various the enterprise life forms. While those five elements of corporate knowledge gene can be easily observed in a certain way, the mode of their interaction is difficult to observe directly, i.e. 
gene external mechanism. That is to say, the structure of its gene has relatively recessive characteristics, which is just the main source of innovation activities, the development of corporate knowledge, and different external behavior.

\subsection{The Fundamental Mechanism for Corporate Knowledge Evolvement-the Self-organizing Mechanism of Corporate Knowledge Genes}

This section is to figure out the answer to the first issue, i.e. the foundation of corporate knowledge evolvement by studying the self-organizing mechanism of the corporate knowledge genes. It covers four typical functions of self-organizing mechanism: self-creation, self-growth, selfreplication and self-adaptation, which lead to the lasting survival and development of an enterprise; the relationship between the self-organizing mechanism and knowledge evolvement process for an enterprise, which manifests as the knowledge development mechanism for an enterprise is that the former lays a foundation for corporate knowledge evolvement process of replicating, mutating, reorganizing and diagnosing the knowledge genes so as to foster the development and innovation of corporate knowledge

\subsection{Corporate Knowledge Development Mechanism-the Gene-replication Mechanism of Corporate Knowledge}

In process of corporate knowledge evolvement, it is because the knowledge genes enable the enterprise to keep its uniqueness from other enterprises by hereditary replication that the enterprise can develop in sustainable way with its knowledge at a stable and orderly state. Corporate knowledge genes are invisible elements, which need a carrier to finish the process of replication and inheritance. Just as the biological gene needs a DNA chain in the process of replication, transcription, translation, and expression, corporate knowledge has its carrier composed of the profit mode, management mode, organizing structure, In this way, the corporate knowledge is reproduced. Consequently, the study on route of genetic replication of corporate knowledge works to make knowledge copying adjustable and selective in order to develop the enterprise in a sustainable way.

\subsection{The First Mechanism of Corporate Knowledge Innovation-the Genetic Mutation of Corporate Knowledge}

Genetic replication of corporate knowledge enables the company to maintain its uniqueness from the others for a sustainable growth and development. However, in case that the environment outside changes, it can't develop further without the variation of corporate knowledge gene knowledge. It refers to decomposition or gene mutation in the development process due to changes in the external environment or internal conditions, causing changes in overall behaviors or certain traits, thus experiencing a process from order to disorder, then to a new order, from being balanced to nonbalanced, then to being balanced again, enabling the enterprises to adapt itself to environmental changes. Whether the enterprise could survive and ultimately thrive lies in its ability to adjust itself to the new environment and bring corporate knowledge mutation of higher value. In addition, feedbacks about the corporate knowledge gene mutation results will be informed. While good knowledge of variation will be strengthened and retained as a guidance of enterprise development, bad one may also lead to new mutation, otherwise the enterprise will be eliminated due to the failure.

\subsection{The Second Mechanism of Corporate Knowledge Innovation-Genetic Reorganization of Corporate Knowledge}

The genetic reorganization of corporate knowledge plays an irreplaceable role in the corporate evolvement. It not only makes a company more adaptable to the environment, but it also facilitates the company to realize a greater leap on a higher platform. In the process of restructuring, new stimuli is a prerequisite for knowledge innovation, knowledge integration process the basis, and 
organic knowledge reconfiguration and diffusion the core of knowledge innovation. It is the new stimuli and the new requirements that drive the corporate knowledge gene adjustment. A the cognitive process will follow to establish the best correlation between knowledge, and thus generate new knowledge, which requires enterprises to test, feedback and adjust in a wider range, and, ultimately achieve the coordination with the market changes to complete the corporate knowledge innovation.

\section{Conclusion}

The era of explosive information demands more and more detailed analysis to knowledge. However, the existing knowledge researches have been mostly completed in the fixed pattern and become more and more rigid and stereotypical, failing to reveal the origin of knowledge. They have explored knowledge innovation by just starting from the outcomes and failed in discovering the dynamics that drive knowledge innovation. At present, the international enterprises pay more and more attention to this issue. In this respect, this paper discusses knowledge innovation from a new perspective, which helps enterprises to re-consider innovation, exploring a path for enterprises to improve their creativity. This study offers a good solution for enterprises to overcome the difficulties when the corporate knowledge is at stake.

\section{Acknowledgements}

Project of Shandong Provincial Bureau of statistics 2016(KT16133); Shandong social science program(15CSGZ15)

\section{References}

[1] Al-Zegaier, H.; Barakat, AS.M., "Mobile portals: An extension to corporate knowledge portals," Information Society (i-Society), 2011 International Conference on, vol., no., pp.388,391, 27-29 June 2011

[2] Gershman, A; Gottsman, E., "Use of hypermedia for corporate knowledge dissemination," System Sciences, 1993, Proceeding of the Twenty-Sixth Hawaii International Conference on, vol.iii, no. pp.411,420 vol.3, 5-8 Jan 2013

[3] Hasan, H.; Meloche, J.A; Pfaff, C.C.; Willis, D., "Beyond Ubiquity: Co-creating Corporate Knowledge with a Wiki," Mobile Ubiquitous Computing, Systems, Services and Technologies, 2007. UBICOMM '07. International Conference on , vol. no. pp.35,40, 4-9 Nov. 2011

[4] Watts, R.J.; Porter, AL., "Mining conference proceedings for corporate technology knowledge management," Technology Management: A Unifying Discipline for Melting the Boundaries, vol. no. pp.349,358, July 31 2005Aug. 42013

[5] Maret, P.; Calmet, J., "Modeling corporate knowledge within the agent oriented abstraction," Cyberworlds, 2004 International Conference on , vol. no.pp.224,231, 18-20 Nov. 2013 